\title{
Representación y narrativa en la producción fílmica colombiana. Aportes para la formación de públicos
}

\section{Representation and narrative in the colombian film production. Contributions to the formation of publics}

\author{
Mónica Eliana García Gil (Universidad Pontificia Bolivariana de Medellín, Colombia) \\ http://dx.doi.org/10.12795/AdMIRA.2010.01.07
}

\section{Resumen:}

Este artículo presenta avances de la investigación Representación de valores sociales y ciudadanos en la producción fílmica colombiana (2003-2009). Un aporte para la formación de audiencias críticas, realizada por Mónica Eliana García G., Arturo Uscátegui M., y Gloria Inés Ceballos H., ${ }^{1}$ docentes investigadores de la Facultad de Comunicación Social para la Paz, de la Universidad Santo Tomás de Bogotá, integrantes del grupo de investigación Comunicación/Paz-Conflicto de la misma universidad. Este escrito abordará las categorías de análisis que soportan la investigación, así como algunos interrogantes y reflexiones que suscita pensar la producción fílmica colombiana en relación con los valores que se llevan a la pantalla, con el fin de brindar pautas para la formación de públicos con competencias lectoras frente a los mensajes audiovisuales. Lo anterior tiene como base metodológica los estudios de recepción y desde la pedagogía de la imagen, la semiótica y el análisis del discurso fílmico.

Palabras claves: Cine colombiano, valores, formación de públicos, representación, alfabetización audiovisual.

\begin{abstract}
:
This article presents advances of the research Representation of social and citizen values in the Colombian film production (2003-2009). A contribution for the formation of critical audiences developed by Mónica Eliana García G., Arturo Uscátegui M., and Gloria Inés Ceballos H., teachers of the Faculty of Social Communication for the Peace, of the Santo Tomás University (Bogotá - Colombia), members of the research group Communication/ Peace- Conflict of the same university. This document will approach the categories of analyses that support the research, as well as some questions and reflections that it provokes to think the colombian film production about relation with the values that are filmed, in order to offer guidelines for the formation of public with reading skills for audiovisual messages. This research takes the reception studies as a methodological base and from the image pedagogy, the semiotic and the analysis of the filmic discourse.
\end{abstract}

Key words: Colombian film, values, critical audiences, representation, media literacy.

${ }^{1}$ Este artículo cuenta con aportes de los co-investigadores, en lo relacionado con los valores y la representación.

Admira no 2 - 2010 
El propósito de esta investigación es establecer cómo el cine construye el relato y la representación en torno a los valores sociales y ciudadanos, en momentos en que la transmisión, enseñanza y formación en valores es asumida también por los productos culturales y los medios de comunicación de masas. Para ello buscará evidenciar las transformaciones y resignificaciones que sufren nociones ligadas a la ética, la moral y lo político al ser parte de los relatos cinematográficos y generar espacios de interacción entre el conocimiento de la academia y el conocimiento que posibilita el cine, frente a valores sociales y ciudadanos, con el fin de formar audiencias críticas frente a los mensajes audiovisuales a partir de pensarnos y reconocernos como colombianos en las imágenes que construye el cine.

\section{Preguntas orientadoras}

Algunas de las preguntas que orientan esta investigación buscan establecer:

¿Cómo se construye la representación de los valores sociales y ciudadanos en el cine colombiano (2003-2009) cuando dimensiones vinculadas a lo político y lo ético asumen las lógicas y las formas enunciativas de los medios de comunicación de masas y la producción audiovisual, al migrar de lo institucional tradicional a las industrias culturales?

¿Cuáles son los valores que se hacen visibles en las películas colombianas?

¿De qué manera es posible establecer relaciones entre los valores sociales y ciudadanos que se representan en el cine colombiano y los existentes en la realidad nacional?

¿Cómo se construyen, se transforman o resignifican los valores sociales y ciudadanos al asumir la forma del relato cinematográfico?

¿Qué tipo de interacción puede darse entre el conocimiento formal (de la academia) y el conocimiento adquirido por medio de los mensajes que difunden productos culturales como el cine?

\section{La muestra seleccionada}

Para el desarrollo de esta investigación se tomó como muestra general las 40 películas colombianas que han sido presentadas en teatros del país durante el periodo 2000-2008, y 
que son consideradas las principales producciones de la década de $2000^{2}$. Posteriormente se hizo una selección de 10 películas bajo los siguientes criterios: tema desarrollado en relación con los valores sociales y ciudadanos, su impacto en la taquilla y los comentarios de la crítica especializada, producciones anteriores de los directores y guionistas seleccionados, y la trascendencia internacional de las películas (participación en festivales, premios). Se incluyeron también algunas de aquellas películas denominadas “de autor” que empiezan a tener presencia en la cinematografía colombiana, en la medida en que en ellas se evidencian propuestas estéticas que exploran nuevas posibilidades formales, diferentes a las del cine colombiano tradicional o bien, de "consumo", que suelen retomar pautas estéticas de formatos televisivos (como la telenovela, por ejemplo).

Al hacer la revisión del material fílmico colombiano realizado en este periodo y la visualización de una muestra inicial de 8 películas, se decidió hacer un mayor énfasis en las películas realizadas a partir de la denominada Ley de Cine (Ley 814 de 2003) que ha posibilitado un incremento en la producción cinematográfica así como en su exhibición y por consiguiente se han hecho visibles numerosos realizadores con nuevas propuestas estéticas y narrativas, muchas veces sobre temas ya conocidos y llevados antes al cine, pero con enfoques y tratamientos diferentes. Por ello el periodo de análisis se delimita entre los años 2003 y 2009, también con la intención de evaluar el impacto de la Ley de Cine en este tiempo.

De este periodo se han seleccionado las siguientes películas:

- La primera noche (2003)

- La sombra del caminante (2004)

- El colombian dream (2006)

- Apocalipsur (2007)

- Perro come perro (2008)

- Los actores del conflicto (2008)

- Yo soy otro (2008)

- $\quad$ PVC $1(2008)$

- Los viajes del viento (2009)

\footnotetext{
2 Datos consultados en la Dirección de cinematografía (www.mincultura.gov.co) y en Cine Colombia (www.cinecolombia.com.co) Fecha de consulta: octubre de 2008
} 
- La pasión de Gabriel (2009)

\section{La apuesta de la investigación: categorías y conceptos}

En relación con las categorías y las bases conceptuales que soportan esta investigación, la apuesta fuerte del grupo de investigación se da en asumir las crisis, las contradicciones y los cuestionamientos que suscitan abordar la representación y los valores y, a su vez, éstos en relación con la construcción discursiva, formal y narrativa del cine colombiano.

Así entonces, en una primera etapa, esta investigación buscará dar cuenta de manera rigurosa y exhaustiva de aquellos valores sociales que en la superficie del relato, en su contenido, “aparecen” explícitos en la muestra seleccionada.

En una fase siguiente, de carácter analítico y hermenéutico, el trabajo se orientará a establecer categorías de relación que puedan dar cuenta de los valores sociales y ciudadanos representados en esa muestra de filmes y la existencia de esos mismos valores en otras formas de representación.

Y en una tercera etapa de esa construcción teórica, donde la categoría de representación es el núcleo la investigación, se buscará dar cuenta de la forma como se construyen, se transforman o resignifican los valores sociales y ciudadanos al asumir la forma del relato cinematográfico.

En cuanto a la representación, se parte de reconocer que estudiar hoy el tema de la representación en relación con el lenguaje y el relato del cine corresponde a la necesidad de encontrar nuevos modelos que permitan comprender la relación entre imagen y realidad, así como a la búsqueda en torno al estatuto de representación que posibilita el cine, en momentos en que el concepto mismo de representación experimenta su crisis, tanto en el arte, la literatura y en los medios de comunicación, como en la política y las instituciones (véase Balandier, 1994; Casetti, 1994; Enaudeau, 1999; Foucault, 1981).

Se busca, entonces, superar aquellas posturas que privilegian un acercamiento al concepto de representación ligado a las metáforas del espejo y del lente neutro frente a la captura y registro de la realidad y acoger los signos de su crisis, de su opacidad y de su estatuto paradojal, como nociones problematizadoras que pueden apuntar a hallazgos de mayor complejidad y apertura. 
La superación de esa comprensión ilusoria e ingenua respecto de la imagen y el relato cinematográfico puede situarse alrededor de los años 50 del siglo pasado en tres autores:

- El cine como develador de instancias del mundo ocultas a la percepción directa (Bazin: 1966),

- El cine como documentador de procesos de la realidad invisibles directamente por su dimensión o velocidad (Kracauer: 1989),

- El cine como una reconstrucción estética de la realidad (Zavattini: 1979).

Desde esa perspectiva, esta investigación también hace una apuesta fuerte: siempre en el terreno del cine narrativo, sólo aquellas obras que se preguntan por los límites de sus medios expresivos, que buscan lo específicamente cinematográfico y que por lo tanto indagan por el estatuto de su representación, en definitiva, sólo aquellos filmes que además de contar historias se proponen en sí mismas como búsqueda formal, elaboran representaciones propiamente cinematográficas de los valores sociales y ciudadanos; entonces quizás -esta es una hipótesis de trabajo- en ese análisis se pueda hacer el otro hallazgo: ¿cuál es la especificidad de la construcción y del contenido de la representación de los valores sociales y ciudadanos que los espectadores realizan, cuando esa construcción y ese contenido provienen de una obra cinematográfica?

En relación con los valores sociales y ciudadanos, esta investigación se ubica en el espacio de tensiones que surgen entre ética y estética a partir del concepto de representación, tomando distancia de posturas moralizantes que determinan una dimensión ética de la estética desde los supuestos efectos socializadores del cine. No interesa tanto acá concebir al cine como una herramienta de divulgación, sensibilización o conocimiento frente a unos determinados valores, sino explorar, de un lado, desde categorías de la estética, la posibilidad de formular nuevas vías de comprensión del cine en tanto forma expresiva desde su representación de valores y de otro, someter a análisis los cambios del contenido, estructura y sentido de los valores sociales y ciudadanos cuando son objeto de la representación cinematográfica.

Desde la antigüedad los valores se discutían en terrenos del bien y el mal, ya desde Aristóteles comienzan a ocupar un lugar preponderante y son entendidos como algo diferente al ser. Los valores deben ser entendidos no como cosas, ni elementos de cosas, sino como propiedades, cualidades sui generis que poseen ciertos objetos llamados bienes 
(Frondizi, 1972:17). Hoy en día el estudio de los valores tiene otra significación y a través de la historia, filósofos y teóricos han enmarcado los valores en el orden de la subjetividad o de la objetividad. Ambas corrientes han tenido aciertos y desaciertos. De acuerdo con Frondizi (1972), por ejemplo, el subjetivismo, mostró la imposibilidad de separar el valor de las reacciones sicológicas, necesidades y apetencias; por su parte, el objetivismo, señaló la necesidad de prestar atención a las cualidades objetivas. La pregunta sobre si tienen todos los valores la misma naturaleza, hace que la mirada cambie de rumbo para que las teorías respondan de distintas maneras acerca de lo que son los valores y en dónde se pueden ubicar en una escala axiológica.

En el caso del cine se revela la coparticipación de los factores objetivos y subjetivos, cuando a unas imágenes fotográficas estáticas (factor objetivo), el sujeto las ve en movimiento por efecto de la proyección (factor subjetivo). Algo parecido sucede con los valores cuando se produce la síntesis de reacciones subjetivas frente a cualidades que se hallan en el objeto. Sin embargo, los factores (el sujeto y el objeto) y la relación (situación), son dinámicos (Frondizi, 1972:198). En esa relación intervienen aspectos internos y externos del sujeto, que tienen que ver con el ambiente físico y cultural (Frondizi,1972:215), que influye directamente con el medio social, pues éste está compuesto por el conjunto de valores de un grupo social y está constituido por estructuras sociales, creencias, convenciones, supuestos, perjuicios, actitudes y comportamientos. También incluye las estructuras políticas, sociales, económicas, con sus recíprocas interrelaciones e influencias.

Además del ambiente físico y el cultural, el factor espacio temporal afecta la forma de asumir los valores, pues constituye el escenario en el que ocurren comportamientos determinados. De lo anterior se deriva el carácter cambiante de los valores, pues éstos no son algo estático, como tampoco lo son las circunstancias que los rodean, sino que, por el contrario, siguiendo a Frondizi (1972:220), se puede afirmar que varían y tienen sentido según situaciones concretas. Pero el valor no se agota en estas situaciones, sino que deja abierta una ancha vía a la actividad creadora del hombre.

Además de lo anterior, resulta necesario ubicar el estudio de los valores en relación con la ética, que se refiere a la reflexión sobre el actuar, y con la moral, entendida como el conjunto de prácticas sociales y culturales adoptadas por un grupo en particular. Así como 
en relación con las dimensiones social y ciudadana de los valores, de las cuales se ocupa esta investigación. Por lo tanto, es necesario hacer referencia a la ética cívica vinculada a formas de organización política donde se promueve el ciudadano capaz de tomar decisiones morales con autonomía. De tal forma que la ética cívica va a posibilitar los valores de la libertad (entendida como autonomía), la igualdad (en la medida en que todos los hombres pueden llegar a ser igualmente autónomos y contar con las mismas oportunidades de desarrollo de sus capacidades) y la solidaridad (o fraternidad, consignada en la Declaración de los Derechos del hombre y del ciudadano). El respeto y protección de los derechos humanos en sus distintas generaciones viene a concretar de algún modo esos valores que componen la ética cívica (Cortina, 1997).

La libertad promueve los derechos llamados de “primera generación”, que corresponden a la libertad de expresión, de conciencia, de asociación, de desplazarse libremente, derecho de propiedad, derecho a participar de las decisiones que se toman en la propia comunidad política.

La igualdad promueve los derechos de “segunda generación”, que corresponden a los económicos, sociales y culturales, como el derecho al trabajo, a un nivel de vida digno, a la educación, a la asistencia sanitaria, al seguro de desempleo y a la jubilación.

La solidaridad promueve los derechos de "tercera generación”, como el derecho a la paz, o a vivir en una sociedad en paz y a vivir en un medio ambiente sano. Por su parte, Ia tolerancia y el respeto a la diferencia, tienen que ver con la predisposición a respetar proyectos ajenos que pueden tener valor, aunque no se compartan. Todos estos valores se potencian a través de una actitud dialógica.

Es importante anotar que no es gratuito ver reflejadas en la pantalla cinematográfica situaciones de violencia y conflicto (físico, político o de poder) que muestran una Colombia atravesada por grupos sociales cuyos valores pretenden imponerse y dominar, aún a costa de la pérdida de la dignidad humana de otros o de las condiciones de igualdad, libertad y solidaridad que deben primar entre los hombres que viven en sociedad. Se puede decir, entonces, que los valores no sólo permiten “poner en condiciones” o hacer habitable la realidad del mundo en que vivimos, sino al mismo tiempo nos ayudan a "acondicionar" nuestra propia realidad personal (Cortina, 1998:12). 
Al llegar a la conjunción entre representación y valores sociales y ciudadanos en el cine colombiano de ficción, surge la pregunta por la relación entre cine y realidad, en la medida en que la comprensión del cine en tanto medio de comunicación y forma estética se sustenta en la relación de representación que asume respecto de la realidad. Hay aquí una apuesta significativa: El proceso de construcción de la representación de los valores, el cambio en las fuentes de la representación de lo institucional (oralidad, escuela, cartilla, gobierno, etc.) a lo masivo (industrias culturales), afecta el estatuto mismo de los valores.

Preguntarse por la construcción cinematográfica de los valores sociales, implica cuestionarse frente a la mediación del cine y cómo tiene lugar allí la representación de éstos, entendiendo acá la representación en una doble perspectiva: de cara a la ética, en cuanto a que los contenidos, su tratamiento y el sentido de los valores se ven afectados por la mediación cinematográfica (lenguaje, relato). Es decir, los valores puestos en pantalla no aparecen en estado puro, son necesariamente una representación y por lo tanto su contenido cambia, diferente a las mediaciones que suponen lo escrito, la oralidad, las clases magistrales o los discursos políticos. Acercarse a la representación desde la perspectiva de la estética, significa analizar los dispositivos que desde la "forma" cine dan lugar a unos valores, cómo se construye el enunciado "valores", a partir de qué estrategias retóricas, propias del lenguaje cinematográfico. Desde esta perspectiva se abre una posibilidad particular, poco explorada, que requiere indagar las tensiones que tienen lugar entre la ética y la estética, para llegar a establecer lo propio de esta construcción.

En este sentido esta investigación indagará por la intervención de la mediación cinematográfica en la representación de los valores en tres niveles o momentos: cuáles son las representaciones que proponen los filmes -contenido de la representación-, cómo son cinematográficamente esas representaciones -forma de la representación-, cómo se constituyen unas nuevas representaciones de valores o se modifican las ya existentes o se articulan a las representaciones de otras fuentes mediadoras de los receptores cinematográficos -efectos del proceso de representación-.

En una fase siguiente de la investigación se configurará un corpus de documentos que desde la institucionalidad contengan políticas y marcos educativos cuyo centro sean los valores sociales, y sobre estos mismos se deberá realizar un análisis del discurso que permita identificar su campo semántico, sus articulaciones con otros discursos y la 
pragmática que se infiera de ellos.

Hasta el momento se ha identificado que los valores presentes en estos documentos están orientados hacia la conformación de una sociedad más equitativa, democrática, incluyente, en paz y con justicia social. Al reconocimiento a la diversidad y la interculturalidad, la reconciliación y la convivencia, así como a la participación y discusión en los asuntos públicos. En el marco de creación de la Cátedra de Derechos Humanos, contemplada en el Plan de Estudios para las instituciones educativas, de conformidad con la Ley General de Educación, se considera educar en la autonomía, la libertad personal, la responsabilidad individual y colectiva, el respeto a la dignidad humana, el pluralismo cultural, ideológico, político y religioso, la tolerancia, la solidaridad y las prácticas democráticas de la participación.

El objetivo que persigue este momento de la investigación es evidenciar la construcción desde la institucionalidad de unos determinados valores sociales y ciudadanos para confrontarlos y compararlos con la representación de ellos mismos en una muestra de la cinematografía nacional reciente.

De otro lado, el interés por aportar a la formación de públicos surge de reconocer una marcada influencia de las imágenes y de los medios audiovisuales en la sociedad contemporánea, así como el desplazamiento en la transmisión, divulgación y enseñanza de valores, patrones de comportamiento y pautas para la comprensión del entorno, de las instituciones tradicionales (Estado, familia, iglesia, escuela) a los medios de comunicación y a las industrias culturales. Contribuyen también el cuestionamiento acerca del papel que cumple la mediación técnica (del cine) frente a los procesos de percepción de la vida social y cotidiana y la necesidad de asumir la responsabilidad de la academia frente al análisis y balance acerca de cómo el cine representa la realidad del país, genera identidad y aporta al reconocimiento de los ciudadanos y de los valores presentes en la sociedad colombiana.

Al abordar el tema de la lectura crítica de medios, en relación con los procesos de codificación y decodificación de los mensajes audiovisuales, no se puede desligar al sujeto decodificador del contexto en el cual está inmerso, tampoco negar la relación existente con sus orígenes culturales, sus condiciones sociales, sus experiencias y conocimientos, lo cual entra en juego al momento de enfrentarse a los contenidos presentados por los medios de comunicación. 
El público, entonces, debe ser considerado como activo, partícipe de un proceso de percepción y de interpretación, más que receptor pasivo o consumidor de medios de manera indistinta. Se podría decir que el espectador imprime su propio sello a los mensajes que recibe, los apropia y los vincula a su vida cotidiana, sin que éstos pierdan su sentido original, pero es necesario tener en cuenta que los mensajes de los medios no tienen sentido en ellos mismos, en la pantalla de cine o de la televisión, tampoco en la página del periódico, sino en el público que los percibe.

El público adoptará diferentes posturas frente a los mensajes y establecerá diferentes relaciones a partir de los contenidos que recibe, los cuales entran a reforzar posiciones preestablecidas y a estimular la construcción activa de otras nuevas, considerando los contenidos explícitos y los supuestos implícitos que subyacen en estos contenidos, por lo tanto las audiencias deberán “ir más allá” de lo que se muestra para así comprender los distintos mensajes que se transmiten y hacer su propia decodificación. De esta forma, no es tanto que el contenido de los mensajes interpele al sujeto, sino que el sujeto también proyecta significados en el texto (Stevenson; 1998, 59)

Por lo tanto, el público que decodifica será considerado, e incluido en la investigación, como aquel conformado por individuos con sus particularidades, inmersos en un contexto determinado, del cual van adquiriendo valores, pensamientos, experiencias e ideologías que entran en juego al momento de decodificar los mensajes audiovisuales, los cuales poseen en sí una carga ideológica (en tanto expresión del pensamiento de un director, un guionista, un productor) y, en muchos casos, política, que pueden ser leídos, o asumidos, por los receptores desde tres posturas o lecturas de acuerdo con su sistema de valores, su experiencia social y cultural, sus marcos ideológicos, su ubicación en la estructura social, entre otros (Morley;1996, Stevenson;1998)

1. Una lectura dominante: en donde se acepta por completo el código dominante transmitido,

2. Una lectura negociada: en donde se acepta en parte el mensaje recibido y se pone en relación con los contextos propios del sujeto. Se modifica el sentido inicial del mensaje.

3. Una lectura de oposición: en donde se impone una interpretación en oposición a la emitida originalmente. Se desecha el código según el cual se codificó el mensaje y se aportan marcos de referencia diferentes. 
Es así como los mensajes de los distintos medios entran en relación (de aceptación, oposición o negociación) con otros conocimientos, discursos, códigos, representaciones y experiencias del sujeto que los recibe, obtenidos a lo largo de su vida y de su contacto con los medios de comunicación, con los mensajes de otras instituciones, personas y otras fuentes de información. Entre todos los contenidos recibidos se hacen comparaciones, selecciones y escogencias para la construcción del sentido final del mensaje acorde con cada usuario y con el reconocimiento que éste hace de las posibilidades expresivas, estéticas y de construcción de la realidad de cada medio.

Esta investigación comparte la intención educativa del Ministerio de Cultura de Colombia en cuanto a que la formación de públicos o construcción de audiencias es de vital importancia dentro de su actual política de apoyo a la cinematografía. El ministerio, en su documento de políticas culturales, destaca la importancia de formar públicos en tanto posibilita "aportar en la cualificación de los espectadores, en el desarrollo de su sentido crítico, en el modelado de sus gustos, en la concientización de sus derechos como consumidores de productos audiovisuales y en la calidad de la información que reciben de las pantallas” (Arbeláez, 2004:63 En: Ministerio de Cultura, 2008).

\section{Consideraciones finales}

Desde la forma cinematográfica, esta investigación opta por reconocer que, en ocasiones, las imágenes poseen un carácter más completo, más denso que la experiencia frente a la realidad sin mediaciones. En otras, al parecer las imágenes sólo ganan ese estatuto de mayor profundidad o significación que la misma realidad, cuando se alejan de su afán de reproductibilidad fiel y se arriesgan con propuestas que van más allá de la percepción “objetiva” y llegan, incluso, a la distorsión.

En cuanto a la relación que en la actualidad se perfila entre las industrias culturales y la educación, es necesario asumir los procesos formativos y educativos más allá del salón de clase. Esto lleva a pensar la educación desde otro punto de vista, menos centralizada en la institucionalidad del acto educativo por vías tradicionales y más en relación con las experiencias, en particular con las generadas por los medios de comunicación. Esto significa apropiar los contenidos de medios como el cine y la televisión para, a través de ellos, posibilitar encuentros que deriven en aprendizajes, diálogos, toma de conciencia y 
reconocimiento de la realidad y el entorno, que pueden ser incorporados por las audiencias en sus procesos cotidianos de conocimiento y reflexión.

Por su parte, la formación de públicos con competencias de lectura frente al lenguaje cinematográfico requiere, retomando a Quiroz (2003:68-69), la necesidad de desarrollar la experiencia perceptiva, es decir, “enseñar a mirar”, enfatizando en el papel de quien observa y el "lugar” desde el que se ve el mensaje audiovisual. Así mismo, es necesario reconocer el potencial expresivo de la imagen y el sentido que es posible otorgarle, por lo tanto, hay que identificar los sentidos de la imagen y quién se los ha dado, para saber desde dónde "habla” la imagen, para descubrir la intención comunicativa que encierra.

El estado actual de esta investigación permite evidenciar que en la producción cinematográfica colombiana reciente muchos de los temas que llegan a la pantalla surgen de la calle y la vida cotidiana urbana. Se hacen visibles personajes que antes no lo eran y audibles las voces de distintos actores de la sociedad colombiana, más allá de las fuentes oficiales tradicionalmente consultadas y privilegiadas, esto debido a que generalmente en países en conflicto la verdad se delega a la institucionalidad y desde allí se legitima. Así mismo, se pone de manifiesto la presencia de una nueva generación de ciudadanos, políticos y realizadores de cine que trabajan por recobrar valores que se han desacralizado y ahora emerge una generación que está poniendo en pantalla y narrando las experiencias propias vividas en los años 80 y principios de los 90, que antes era imposible contar ya fuera por la censura, el peligro o el miedo a hablar de aquello que se vivió en estos años. Lo anterior permite que se puedan atribuir al cine otras funciones, no solamente las del entretenimiento o la distracción, sino que adquiere un papel fundamental para socializar la realidad en conflicto que vive el país, teniendo en cuenta que en comunidades signadas por el dolor que deja la violencia y las distintas formas de conflicto, es necesario hacer el duelo, sentir el dolor y reconocer los alcances que éstas situaciones han tenido, con el fin de disipar los temores, hablar y poner en común aquello que ha sucedido como un mecanismo de reconocimiento, aceptación y superación. De esta forma, el cine contribuye a narrar las distintas formas de conflicto que vive Colombia y posibilita, así mismo, diferentes elaboraciones frente a una realidad a la que, por estar tan familiarizados, a veces se niega, se olvida o se es indiferente. 
El grupo que lidera esta investigación cree en la gran oportunidad que brinda la situación actual del cine en Colombia para generar debates, búsquedas y cuestionamientos en torno a los mensajes, propuestas estéticas y narrativas que desde allí se están construyendo, sus impactos en la sociedad y sus aportes para la lectura y comprensión de los modos de ser, pensar y actuar en torno a la realidad nacional con sus matices, al tiempo que se evidencian las relaciones entre ética, política y estética audiovisual, que están presentes en los productos fílmicos colombianos más recientes.

Esto desde una concepción de cine como escenario que posibilita que emerjan nuevas formas narrativas para contar realidades locales que pueden ser a su vez globales. Un cine que permita el reconocimiento de la realidad y de los actores involucrados en ella, aunque a veces desgarre, confronte y cuestione. Y una mirada a las estéticas propias, así como a los temas comunes presentes en las ciudades colombianas y latinoamericanas, que contribuya a tener una idea de país y de región a partir del reconocimiento y la consolidación de la identidad que las imágenes del cine hacen posible.

\section{Referencias bibliográficas}

Arbeláez, Ramiro (2004) “El arte de la exhibición cinematográfica”. En: Manual de gestión

de salas alternas de cine. Ministerio de Cultura, Dirección de Cinematografía. Bogotá, octubre de 2004. Citado por: Ministerio de cultura (2008). Políticas culturales. Documento de trabajo. Bogotá.

Balandier, G. (1994) El poder en escenas. De la representación del poder al poder de la representación. Barcelona: Paidós.

Bazin, André (1966) ¿Qué es el cine? Barcelona: Rialp.

Casetti, Francesco (1994) Teorías del cine. Madrid: Cátedra.

Cortina, Adela (1998). El mundo de los valores. “Ética mínima” y educación. Bogotá: El

Búho Ltda.

Enaudeau, Corinne (1999) La paradoja de la representación. Buenos Aires: Paidós.

Foucault, Michel (1981) Las palabras y las cosas. Buenos Aires: Siglo XXI.

Frondizi, Risieri (1972). ¿Qué son los valores? México: Fondo de Cultura Económica.

Tercera edición 
Kracauer, Siegfried (1989) Teoría del cine, la redención de la realidad física. Barcelona: Paidós.

Plataforma colombiana de Derechos Humanos, Democracia y Desarrollo (2008). Retos para la política pública en Bogotá. Bogotá.

Morley, David (1996) Televisión, audiencias y estudios culturales. Buenos Aires: Amorrortu.

Quiroz, María Teresa (2003). Aprendizaje y comunicación en el siglo XXI. Bogotá: Norma. Ricoeur, Paul (2006). Proyecto universal y multiplicidad de las herencias. En: Jérôme Bindé (2006) ¿Hacia dónde se dirigen los valores? Coloquios del Siglo XXI. México: Fondo de Cultura Económica.

Roth D., André-Noël (2006) Discurso sin compromiso. Bogotá: Ediciones Aurora.

Stevenson, Nick (1998) Culturas mediáticas. Teoría social y comunicación masiva. Buenos Aires: Amorrortu.

Zavattini (1979) En: Casetti, Francesco (1994) Teorías del cine. Madrid: Cátedra. 